\title{
Association between body mass index and blood pressure levels across socio-demographic groups and geographical settings: analysis of pooled data in Peru
}

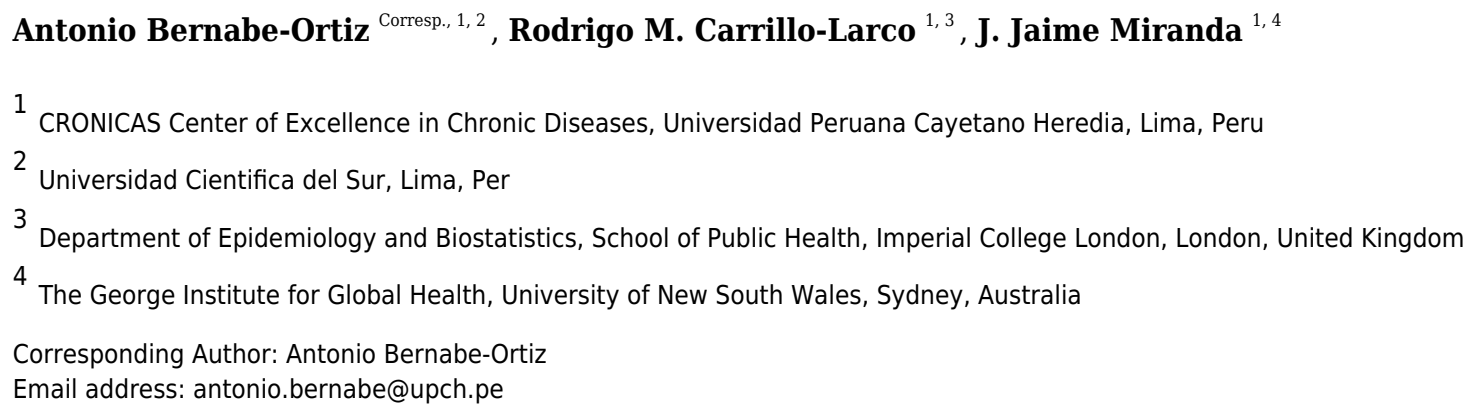

Background: Understanding the relationship between BMI and blood pressure requires assessing whether this association is similar or differs across population groups. This study aimed to assess the association between body mass index (BMI) and blood pressure levels, and how these associations vary between socioeconomic groups and geographical settings. Methods: Data from the National Demographic Health Survey of Peru from 2014 to 2019 was analyzed considering the complex survey design. The outcomes were levels of systolic (SBP) and diastolic blood pressure (DBP), and the exposure was BMI. Exposure and outcomes were fitted as continuous variables in a non-linear quadratic regression model. We explored effect modification by six socioeconomic and geographical variables (sex, age, education level, socioeconomic position, study area, and altitude), fitting an interaction term between each of these variables and BMI. Results: Data from 159,940 subjects, mean age 44.4 (SD: 17.1), 54.6\% females, was analyzed. A third (34.0\%) of individuals had $\geq 12$ years of education, $24.7 \%$ were from rural areas, and $23.7 \%$ lived in areas located over 2500 meters above sea level. In the overall sample mean BMI was 27.1 (SD: 4.6) kg/m², and mean SBP and DBP were 122.5 (SD: 17.2) and 72.3 (SD: 9.8) mmHg, respectively. In the multivariable models, greater BMI levels were associated with higher SBP ( $p$-value <0.001) and DBP ( $p$-value <0.001). There was strong evidence that sex, age, education level, and altitude were effect modifiers of the association between BMI and both SBP and DBP. In addition to these socio-demographic variables, socioeconomic position and study area were also effect modifiers of the association between BMI and DBP, but not SBP. Conclusions: The association between BMI and levels of blood pressure is not uniform on a range of socio-demographic and geographical population groups. This characterization can inform the understanding of the epidemiology and rise of blood 
pressure in a diversity of low-resource settings. 
1 Association between body mass index and blood pressure levels across socio-demographic

2 groups and geographical settings: analysis of pooled data in Peru

4 Antonio Bernabe-Ortiz ${ }^{1,2 *}$, Rodrigo M. Carrillo-Larco ${ }^{1,3}$, J. Jaime Miranda ${ }^{1,4}$

5 1. CRONICAS Center of Excellence in Chronic Diseases, Universidad Peruana Cayetano 6 Heredia, Lima, Peru

7 2. Universidad Científica del Sur, Lima, Peru

8 3. Department of Epidemiology and Biostatistics, School of Public Health, Imperial College 9 London, London, United Kingdom.

10 4. The George Institute for Global Health, University of New South Wales, Sydney, Australia

12 * Corresponding author:

13 Antonio Bernabe-Ortiz, MD, MPH, $\mathrm{PhD}$

14 CRONICAS Center of Excellence in Chronic Diseases, Universidad Peruana Cayetano Heredia, 15 Av. Armendariz 445, Lima, Peru

16 Email: Antonio.Bernabe@upch.pe

17

18 


\section{Abstract}

20 22 23

\section{Background:}

Understanding the relationship between BMI and blood pressure requires assessing whether this association is similar or differs across population groups. This study aimed to assess the association between body mass index (BMI) and blood pressure levels, and how these associations vary between socioeconomic groups and geographical settings.

\section{Methods:}

Data from the National Demographic Health Survey of Peru from 2014 to 2019 was analyzed considering the complex survey design. The outcomes were levels of systolic (SBP) and diastolic blood pressure (DBP), and the exposure was BMI. Exposure and outcomes were fitted as continuous variables in a non-linear quadratic regression model. We explored effect modification by six socioeconomic and geographical variables (sex, age, education level, socioeconomic position, study area, and altitude), fitting an interaction term between each of these variables and BMI.

\section{Results:}

Data from 159,940 subjects, mean age 44.4 (SD: 17.1), 54.6\% females, was analyzed. A third (34.0\%) of individuals had $\geq 12$ years of education, $24.7 \%$ were from rural areas, and $23.7 \%$ lived in areas located over 2500 meters above sea level. In the overall sample mean BMI was 27.1 (SD: 4.6) kg/m², and mean SBP and DBP were 122.5 (SD: 17.2) and 72.3 (SD: 9.8) $\mathrm{mmHg}$, respectively. In the multivariable models, greater BMI levels were associated with higher SBP (p-value $<0.001)$ and DBP ( $p$-value $<0.001)$. There was strong evidence that sex, age, education level, and altitude were effect modifiers of the association between BMI and both SBP and DBP.

1 In addition to these socio-demographic variables, socioeconomic position and study area were 2 also effect modifiers of the association between BMI and DBP, but not SBP.

\section{Conclusions:}


44 The association between BMI and levels of blood pressure is not uniform on a range of socio45 demographic and geographical population groups. This characterization can inform the 46 understanding of the epidemiology and rise of blood pressure in a diversity of low-resource 47 settings.

48

49 Key words: blood pressure; body mass index; hypertension; obesity 
50 Introduction

51 Globally, the number of adults living with raised blood pressure has increased from 594 million in 1975 to 1.13 billion in 2015 (NCD Risk Factor Collaboration (NCD-RisC) 2017a); and this condition is responsible for 9.4 million deaths worldwide (Lim et al. 2012), disproportionally affecting low- and middle-income countries. On the other hand, the alarming increase of body mass index (BMI) during the last decades (NCD Risk Factor Collaboration (NCD-RisC) 2017b), accompanied by the increase in the prevalence of overweight and obesity, will most likely pair the raise in blood pressure levels.

In Latin America, despite the high prevalence of cardiometabolic risk factors (NCD Risk Factor 59 Collaboration (NCD-RisC) - Americas Working Group 2020), their distribution is not homogenous between countries introducing additional particularities in shaping prevention and control strategies for raised blood pressure across settings. The increases in the levels of blood pressure and BMI are two ongoing global phenomena observed in recent decades, and understanding the patterning of its linkages is required to better counter them. This is of utmost importance as raises in BMI have been predominantly driven by increases in rural areas (NCD Risk Factor Collaboration (NCD-RisC) 2019).

BMI has been positively associated with both systolic (SBP) and diastolic (DBP) blood pressure (Drøyvold et al. 2005; Linderman et al. 2018). Although previous studies have described this association, many of these reports arise from high-income countries (Danon-Hersch et al. 2007; Gelber et al. 2007; Hubert et al. 1983), and from Asia and Africa (Linderman et al. 2018; Tesfaye et al. 2007), with limited representation from Latin American settings.

Understanding the relationship between BMI and blood pressure requires assessing whether this association is similar or differs across population groups. Peru, a middle-income country located in South America, is a region with pronounced socioeconomic disparities. These inequalities are paired with a unique geographical diversity with populations living across a range of low and high-altitude, and rural and urban areas. These sociodemographic factors can influence how the BMI is associated with blood pressure levels. Therefore, we aimed to assess the association between BMI and both SBP and DBP, and determine whether this association varies between different subgroups of the population. 
80 Methods

\section{Study design and population}

82 Data from Peru's National Demographic Health Survey (ENDES, Spanish acronym) from 2014

83 to 2019 was utilized in this analysis. The ENDES is a nationally representative population-based 84 survey conducted annually. Since 2014, the ENDES has also included a health questionnaire and 85 blood pressure measurements, on a yearly basis.

86 The ENDES sampling followed a bietapic approach. In rural areas, the primary sampling units were clusters of 500 to 2000 individuals and the secondary sampling units were the households within each of these clusters. In urban areas, the sampling units were blocks or groups of blocks with more than 2000 individuals and an average of 140 households; the secondary sampling units were also households as in rural settings. Details about the sampling process are described in detail elsewhere (Instituto Nacional de Estadistica e Informatica 2015). For this analysis we included data from participants aged 20 years and above (as adolescence, i.e., up to 19 years, may affect body distribution and for instance BMI) with complete BMI and blood pressure measures.

\section{Variables definition}

\section{Outcomes:}

97 The outcomes were both SBP and DBP. To guarantee that only plausible measurements were 98 included in analyses, a cut point was used as in previous studies (NCD Risk Factor Collaboration (NCD-RisC) 2017a): SBP measurements should be $\geq 70$ and $\leq 270 \mathrm{mmHg}$, whereas DBP measurements should be $\geq 50$ and $\leq 150 \mathrm{mmHg}$. The no-plausible values were dropped from analyses.

102 Blood pressure was measured using a digital monitor (OMRON, model HEM-713), validated for adult populations (Takahashi et al. 2015). Two types of cuffs were used depending on the arm circumference of participants: standard arm (220 to $320 \mathrm{~mm}$ ) and thicker arm (330 to $430 \mathrm{~mm}$ ). Blood pressure measurements were assessed twice with the participant sitting and their right arm resting on a flat surface at the heart level. The first measurement was taken after a resting period 
108 Nacional de Estadistica e Informatica 2018). The average of the two assessments was used in the

109 analysis only if the difference between both measurements did not exceed $10 \mathrm{mmHg}$. Those

110 exceeding that threshold were dropped from further analyses.

\section{Exposure:}

112 BMI $\left(\mathrm{kg} / \mathrm{m}^{2}\right)$, as a continuous variable, was defined as weight $(\mathrm{Kg})$ divided by height squared $113\left(\mathrm{~m}^{2}\right)$. Participants' weight and height were measured following standard procedures (Instituto 114 Nacional de Estadistica e Informatica 2018), with the subject without shoes. To guarantee that 115 only plausible BMI measurements were included in analyses, a cut point was used as in previous 116 studies (Linderman et al. 2018): BMI $\geq 10 \mathrm{~kg} / \mathrm{m}^{2}$ and $<60 \mathrm{~kg} / \mathrm{m}^{2}$.

\section{Effect modifiers:}

118 A set of socio-demographic and geographical variables were also included as confounders and 119 potential effect modifiers of the association of interest. We included sex (female vs. male); age 120 (as continuous variable, but also categorized as $<40,40-59$, and $\geq 60$ years); education level (in

121 years, $<7,7-11$, and $\geq 12$ years), and socioeconomic position (defined in tertiles based on a 122 wealth index). This wealth index was calculated by the National Institute of Statistics and 123 Informatics (INEI, Spanish acronym) based on assets and services that the participant reported 124 having in the household (Rutstein \& Johnson 2004). As geographical variables we considered 125 area (rural vs. urban) and altitude $(\leq 500,501-2500$, and $\geq 2501$ meters above the sea level 126 [m.a.s.1.]).

\section{Other variables:}

128 For description of the participants characteristics in our study sample, we also provide 129 information on hypertension, overweight and obesity. The ENDES collected self-reported 130 information about whether the participant had a previous diagnosis of hypertension and if 131 participants were receiving any anti-hypertensive medication. Therefore, hypertension was also 132 defined as $\mathrm{SBP} \geq 140 \mathrm{mmHg}$ or $\mathrm{DBP} \geq 90 \mathrm{mmHg}$, or was diagnosed with hypertension 133 (Chobanian et al. 2003). Standard BMI thresholds were used to estimate prevalence of 134 overweight and obesity: BMI $\geq 25$ and $<30 \mathrm{~kg} / \mathrm{m}^{2}$ for overweight, and BMI $\geq 30 \mathrm{~kg} / \mathrm{m}^{2}$ for 135 obesity, whereas BMI $<25 \mathrm{~kg} / \mathrm{m}^{2}$ was classified as normal.

\section{Statistical methods}


137 Analyses were performed using STATA 13 for Windows (StataCorp, College Station, TX, US).

138 Descriptive statistics and estimates were calculated considering the complex survey design using 139 sample strata, primary sampling units and sampling weights, including the analysis of 140 subpopulation groups (West et al. 2008). We decided to pool data to maximize sample size while 141 also decreasing statistical uncertainty; this process is consistent with large and global data 142 pooling endeavors conducted before (e.g., IHME/GBD, NCD-RisC, among others).

143 Initially, description of continuous variables was conducted using mean and standard deviation 144 (SD), whereas for categorical variables we used absolute and relative frequencies. Prevalence of 145 hypertension, overweight, and obesity, and their respective 95\% confidence intervals (95\% CI), 146 were also estimated. Comparisons were performed using Chi-squared test corrected for the 147 survey design with the second-order correction of Rao and Scott (Rao \& Scott 1984) for 148 categorical variables, whereas t-test was used for numeric variables.

149 To assess the association between BMI and blood pressure, a non-linear regression model (more 150 details are provided in the Supporting Information file: Statistical approach) was built as 151 suggested in literature (Kerry et al. 2005). An adjusted model was also created including 152 coefficients for categorical variables (i.e., sex, education level, socioeconomic position, study 153 area and altitude), whereas age was included as continuous variable by other studies (NCD Risk 154 Factor Collaboration (NCD-RisC) - Americas Working Group 2020; NCD Risk Factor 155 Collaboration (NCD-RisC) 2017a; NCD Risk Factor Collaboration (NCD-RisC) 2017b).

156 To explore effect modification, i.e., to evaluate whether the association between BMI and levels 157 of blood pressure vary by specific population groups, i.e., by socio-demographic and 158 geographical variables, an interaction term between each socio-demographic variable and BMI 159 (and its quadratic term) was included (see Supporting Information file: Statistical approach). 160 Effect modification was assessed using the testparm, a post-estimation command in STATA and 161 a p-value $<0.05$ was considered significant. When conducting multivariable model stratified by 162 subgroups, we excluded the variable defining that subgroup from the list of potential 163 confounders. Collinearity was evaluated using the tolerance test in STATA. Marginal means of 164 blood pressure levels for specified fixed values of socio-demographic variables were calculated 165 from each fitted model and presented as figures (and also tables) to verify variation of the 166 association of interest (Graubard \& Korn 1999; Williams 2012). Values of BMI higher than 50 
$167 \mathrm{~kg} / \mathrm{m}^{2}$ were truncated to avoid the impact of few values on results $(<0.1 \%$ of subjects had values 168 of $\left.\mathrm{BMI}>50 \mathrm{~kg} / \mathrm{m}^{2}\right)$.

169 Finally, sub-analyses were also conducted to assess the association of interest (overall and by 170 sub-population group) by excluding individuals who reported taking anti-hypertensive 171 medication as this can bias results.

\section{Ethics}

173 The data used in our study is anonymous and freely available to the general public and does not 174 reveal any personal identifiable information, and consequently this study does not represent an 175 ethical risk for participants. The INEI, a Peruvian government organization, is responsible for the 176 annual collection of ENDES data. This institution requested the consent of participants before 177 the survey.

178 
181 Characteristics of the study population

182 Data from a total of 203,880 individuals was available for the analysis utilizing ENDES annual 183 evaluations over the study period. Of them, information from 22,646 (11.1\%) aged <20 years; 184 2,734 (1.3\%) pregnant women; 15,519 (7.6\%) without blood pressure; 3,007 (1.5\%) without 185 BMI results, and $34(<0.1 \%)$ with $\mathrm{BMI} \geq 60 \mathrm{~kg} / \mathrm{m}^{2}$ were excluded from our analysis. Thus, a total 186 of 159,940 subjects, mean age 44.4 (SD: 17.1), 54.6\% females, were analyzed. Of note, only a 187 third (34.0\%) of individuals had $\geq 12$ years of education, $24.7 \%$ were from rural areas, and $23.7 \%$ 188 lived in areas located over 2500 m.a.s.1.

189 Mean BMI was 27.1 (SD: 4.6) $\mathrm{kg} / \mathrm{m}^{2}$ in the overall sample. The prevalence of overweight was $19041.6 \%$ (95\% CI: 41.2\% - 42.0\%), and the prevalence of obesity was $23.5 \%$ (95\% CI: $23.1 \%-$ 191 23.9\%). Similarly, mean SBP and DBP were 122.5 (SD: 17.2) and 72.3 (SD: 9.8) $\mathrm{mmHg}$, 192 respectively, whilst the prevalence of hypertension was $21.2 \%(20.8 \%-21.6 \%)$.

193 When comparing socio-demographic characteristics by sex, males had higher number of years of 194 education and greater blood pressure levels and hypertension rates compared to females. 195 Conversely, females had higher body mass index and greater obesity rates (Table 1).

\section{Association between body mass index and blood pressure levels}

197 Greater BMI levels were associated with increasing SBP (p-value <0.001) and DBP (p-value $<0.001$ ) values in multivariable models (Figure 1 A-B).

199 The increase of SBP per unit BMI varied from 0.05 to $1.8 \mathrm{mmHg} /\left(\mathrm{kg} / \mathrm{m}^{2}\right)$, whereas the increase 200 of DBP ranged from 0.09 to $1.13 \mathrm{mmHg} /\left(\mathrm{kg} / \mathrm{m}^{2}\right)$. Estimates for specific BMI cut points are 201 shown in Table 2 and Table 3 (by sex), where the highest values of both, SBP and DBP, were 202 reached at BMI of $45 \mathrm{~kg} / \mathrm{m}^{2}$.

203 The association between BMI and SBP differed by different socio-demographic variables(Fig 2 204 A-F), it was stronger among males (p-value for interaction term <0.001), among older 205 individuals ( $p$-value for interaction term $<0.001$ ), those less educated ( $p$-value for interaction 206 term $=0.001)$, and among those living under 500 meters above sea level ( $\mathrm{p}$-value for interaction 207 term $=0.005)$. On the other hand, all the socio-demographic and geographical variables studied 
208 were effect modifiers of the association between BMI and DBP (Fig 3 A-F): it was stronger 209 among males ( $\mathrm{p}$-value for interaction terms $<0.001$ ), among older individuals ( $\mathrm{p}$-value for 210 interaction term $<0.001$ ), better educated ( $\mathrm{p}$-value for interaction terms $<0.001$ ), those with low 211 socioeconomic position ( $p$-value for interaction terms $<0.001$ ), those in urban areas ( $p$-value for 212 interaction terms $<0.001$ ), and among those living at high altitude (p-value for interaction terms $213<0.001)$. Coefficients and 95\% CI are shown in the Supporting Information file: Tables S1 to S7.

214 All the tolerance values for collinearity were $<5$.

215 When the analyses were conducted excluding subjects taking anti-hypertensive medication, 216 results and figures were similar to those shown as main results as only about a third (30.4\%) of 217 participants with hypertension reported taking antihypertensive pharmacological medication 218 (Details in the Supporting Information file: Tables S8 to S12).

219 
220 Discussion

221 Using nationally representative data from Peru, accrued over five years in approximately 222160,000 subjects, we advance the evidence reported on the association between BMI and blood 223 pressure by exploring the effect of relevant socio-economic health determinants, namely sex, 224 age, education level, socioeconomic position, study area, and altitude, much needed for adequate 225 resource allocation. Whilst the effect modification in the relationship between BMI and DBP was 226 present in all of these subgroups, socioeconomic position and study area were not effect 227 modifiers in the association between BMI and SBP.

228 The global rise of levels of BMI and blood pressure calls for paying attention at particular 229 groups; hence, our results disaggregated by socio-demographic groups show clear patterns of 230 association between SBP and DBP when BMI increases. These results, for countries in 231 transition, can inform tailored prevention and control strategies to counter the rise in levels of

232 blood pressure and BMI, focusing on specific groups to yield higher prevention gains and further 233 population-wide benefits. It is notorious the role of sex, but the peculiarities of area, including 234 living in high altitude areas, as well as education, may be also important. Interventions or 235 treatment allocation to improve BMI and blood pressure may not need different approaches by 236 different socio-demographic variables, but could benefit of gender-based tailoring to maximize 237 its impact.

238 Globally, mean blood pressure levels are higher in African countries, and Peru ranks among the 239 countries with lowest mean blood pressure in the world (NCD Risk Factor Collaboration (NCDRisC) - Americas Working Group 2020; NCD Risk Factor Collaboration (NCD-RisC) 2017a).

241 Much of the literature on the relationship between BMI and blood pressure arises from Asia and 242 some parts of Africa (Danon-Hersch et al. 2007; Tesfaye et al. 2007). Importantly, a nationwide 243 study of 1.7 million Chinese adults explored similar relationships between BMI and blood 244 pressure across a diversity of groups (Linderman et al. 2018), with some notorious observations 245 contrasting our findings. Compared to our Peruvian sample, Chinese individuals had 246 approximately $2.5 \mathrm{~kg} / \mathrm{m}^{2}$ units lower than Peruvians (24.7 vs. $27.1 \mathrm{~kg} / \mathrm{m}^{2}$ ), yet their SBP was 14 $247 \mathrm{mmHg}$ higher (136.5 vs. $122.4 \mathrm{mmHg}$ ), and DBP was $9 \mathrm{mmHg}$ higher ( 81.1 vs. $72.2 \mathrm{mmHg}$ ). 248 While both studies confirm a relationship between BMI and blood pressure across a range of 249 groups, the trajectories of SBP values in Peruvians range between 100 and $140 \mathrm{mmHg}$ in all the 
250 groups studied (Fig 2), whereas Chinese SBP values reach up to $150 \mathrm{mmHg}$ and $160 \mathrm{mmHg}$ in 251 some cases (Linderman et al. 2018). In Latin America, one previous study from Brazil, focused 252 on a single state, analyzed the association between two anthropometric indexes, waist 253 circumference and BMI, and hypertension and found both indexes associated with hypertension, 254 but showed a low sensitivity as predictors (Peixoto Mdo et al. 2006).

255 Our observations, benefiting from nationwide representative data, are useful not only in 256 describing the patterns of the relationships between BMI and blood pressure, but also in 257 adequately informing policies. Such tailored policies are needed as premature non-avertable 258 mortality from non-communicable diseases decreased slightly or stagnated in most regions, and 259 rose in the region of the Americas (Martinez et al. 2020). Therefore, characterizing the patterns 260 of the BMI-blood pressure relationship are crucial in the Latin American region, particularly 261 given the high level of heterogeneity in the transition of major cardiovascular risk factors in the 262 region (NCD Risk Factor Collaboration (NCD-RisC) - Americas Working Group 2020).

263 Peru is a middle-income country located in South America, with a fragile and fragmented health 264 care system, with poor response to the challenges of chronic conditions, and for instance, may 265 not be prepared to tackle the burden of increasing BMI and blood pressure levels (Loret de Mola 266 et al. 2014). A recent manuscript demonstrated an increasing age-standardized prevalence of hypertension in the last years in Peru, whereas the rates of disease awareness and controlled hypertension have declined (Villarreal-Zegarra et al. 2020). Our results demonstrated slightly change in blood pressure estimates in the overall sample and when excluding those with antihypertensive medication pointed out the low rates of appropriate treatment and control (ZavalaLoayza et al. 2016). Thus, a thoroughly planned and balanced policy would be needed to provide care to those who most needed, including appropriate hypertension diagnosis and treatment.

273 This study benefits from data derived from a nationally representative survey of adult population, 274 with objective measurements, and a robust modeling approach that goes beyond linear 275 associations. Our study expands to disentangle relationships across a diversity of socioeconomic 276 and geographical population groups, much needed to characterize the epidemiology of BMI and 277 blood pressure, and to inform policies. Despite this, we are aware of certain limitations including 278 the cross-sectional nature of the data, together with potential for reverse causality. Given that 279 both, obesity and high blood pressure are established global public health priorities, both require 
280 urgent action to prevent their associated complications. Also, the graphical nature of the BMI-

281 blood pressure trajectories should be interpreted with caution as comparisons of levels of blood

282 pressure across BMI groups are not necessarily correct, but rather the result of calculations of

283 blood pressure values given a value of BMI. Whilst we cannot ascertain that a give group has a

284 number of blood pressure units, higher or lower, than other group, the trajectories are useful in

285 identifying potential groups to target action, e.g., males compared to females. In addition, across

286 the years, the sampling frame of the ENDES survey has changed; for example, the sampling

287 frame of the last two years is not the same as in the previous years. However, where relevant, we

288 used the year-specific sampling weights, stratum and sampling units. Other variables (e.g.,

289 dietary consumption, physical activity, and comorbidities) were not included in the models as

290 they were not available.

291

292 Conclusions

293 In conclusion, greater BMI is associated with higher blood pressure levels in Peru, but this 294 association is not uniform across a range of socio-demographic and geographical population 295 groups. These results may contribute to prevention and control strategies to counter the rise in 296 levels of blood pressure and BMI, focusing on specific groups to yield higher prevention gains 297 and further population-wide benefits.

298

299 Acknowledgments

300 RMC-L is supported by a Wellcome Trust International Training Fellowship, London, UK 301 (214185/Z/18/Z).

302 


\section{References}

305

306

307

308

309

310

311

312

313

314

315

316

317

318

319

320

321

322

323

324

325

326

327

328

329

330

331

332

333

334

335

336

337

338

339

340

341

342

343

344

345

346

347

348

Chobanian AV, Bakris GL, Black HR, Cushman WC, Green LA, Izzo JL, Jr., Jones DW, Materson BJ, Oparil S, Wright JT, Jr., and Roccella EJ. 2003. The Seventh Report of the Joint National Committee on Prevention, Detection, Evaluation, and Treatment of High Blood Pressure: the JNC 7 report. Jama 289:2560-2572. 10.1001/jama.289.19.2560

Danon-Hersch N, Chiolero A, Shamlaye C, Paccaud F, and Bovet P. 2007. Decreasing association between body mass index and blood pressure over time. Epidemiology 18:493-500. 10.1097/EDE.0b013e318063eebf

Drøyvold WB, Midthjell K, Nilsen TI, and Holmen J. 2005. Change in body mass index and its impact on blood pressure: a prospective population study. Int $J$ Obes (Lond) 29:650-655. 10.1038/sj.ijo.0802944

Gelber RP, Gaziano JM, Manson JE, Buring JE, and Sesso HD. 2007. A prospective study of body mass index and the risk of developing hypertension in men. Am J Hypertens 20:370-377. 10.1016/j.amjhyper.2006.10.011

Graubard BI, and Korn EL. 1999. Predictive margins with survey data. Biometrics 55:652-659. 10.1111/j.0006-341x.1999.00652.x

Hubert HB, Feinleib M, McNamara PM, and Castelli WP. 1983. Obesity as an independent risk factor for cardiovascular disease: a 26-year follow-up of participants in the Framingham Heart Study. Circulation 67:968-977. 10.1161/01.cir.67.5.968

Instituto Nacional de Estadistica e Informatica. 2015. Peru: Encuesta Demografica y de Salud Familiar ENDES 2014. Lima, Peru: INEI.

Instituto Nacional de Estadistica e Informatica. 2018. Manual de la entrevistadora - Encuesta demográfica y de salud familiar. Lima, Peru: INEI.

Kerry SM, Micah FB, Plange-Rhule J, Eastwood JB, and Cappuccio FP. 2005. Blood pressure and body mass index in lean rural and semi-urban subjects in West Africa. $J$ Hypertens 23:1645-1651. 10.1097/01.hjh.0000177536.53409.1a

Lim SS, Vos T, Flaxman AD, Danaei G, Shibuya K, Adair-Rohani H, Amann M, Anderson HR, Andrews KG, Aryee M, Atkinson C, Bacchus LJ, Bahalim AN, Balakrishnan K, Balmes J, Barker-Collo S, Baxter A, Bell ML, Blore JD, Blyth F, Bonner C, Borges G, Bourne R, Boussinesq M, Brauer M, Brooks P, Bruce NG, Brunekreef B, Bryan-Hancock C, Bucello C, Buchbinder R, Bull F, Burnett RT, Byers TE, Calabria B, Carapetis J, Carnahan E, Chafe Z, Charlson F, Chen H, Chen JS, Cheng AT, Child JC, Cohen A, Colson KE, Cowie BC, Darby S, Darling S, Davis A, Degenhardt L, Dentener F, Des Jarlais DC, Devries K, Dherani M, Ding EL, Dorsey ER, Driscoll T, Edmond K, Ali SE, Engell RE, Erwin PJ, Fahimi S, Falder G, Farzadfar F, Ferrari A, Finucane MM, Flaxman S, Fowkes FG, Freedman G, Freeman MK, Gakidou E, Ghosh S, Giovannucci E, Gmel G, Graham K, Grainger R, Grant B, Gunnell D, Gutierrez HR, Hall W, Hoek HW, Hogan A, Hosgood HD, 3rd, Hoy D, Hu H, Hubbell BJ, Hutchings SJ, Ibeanusi SE, Jacklyn GL, Jasrasaria R, Jonas JB, Kan H, Kanis JA, Kassebaum N, Kawakami N, Khang YH, Khatibzadeh S, Khoo JP, Kok C, Laden F, Lalloo R, Lan Q, Lathlean T, Leasher JL, Leigh J, Li Y, Lin JK, Lipshultz SE, London S, Lozano R, Lu Y, Mak J, Malekzadeh R, Mallinger L, Marcenes W, March L, Marks R, Martin R, McGale P, McGrath J, Mehta S, Mensah GA, Merriman TR, Micha R, Michaud C, Mishra V, Mohd Hanafiah K, Mokdad AA, Morawska L, Mozaffarian D, Murphy T, Naghavi M, Neal B, Nelson PK, Nolla JM, Norman R, Olives C, Omer SB, Orchard J, Osborne R, Ostro B, Page A, Pandey KD, 
Parry CD, Passmore E, Patra J, Pearce N, Pelizzari PM, Petzold M, Phillips MR, Pope D, Pope CA, 3rd, Powles J, Rao M, Razavi H, Rehfuess EA, Rehm JT, Ritz B, Rivara FP, Roberts T, Robinson C, Rodriguez-Portales JA, Romieu I, Room R, Rosenfeld LC, Roy A, Rushton L, Salomon JA, Sampson U, Sanchez-Riera L, Sanman E, Sapkota A, Seedat S, Shi P, Shield K, Shivakoti R, Singh GM, Sleet DA, Smith E, Smith KR, Stapelberg NJ, Steenland K, Stöckl H, Stovner LJ, Straif K, Straney L, Thurston GD, Tran JH, Van Dingenen R, van Donkelaar A, Veerman JL, Vijayakumar L, Weintraub R, Weissman MM, White RA, Whiteford H, Wiersma ST, Wilkinson JD, Williams HC, Williams W, Wilson N, Woolf AD, Yip P, Zielinski JM, Lopez AD, Murray CJ, Ezzati M, AlMazroa MA, and Memish ZA. 2012. A comparative risk assessment of burden of disease and injury attributable to 67 risk factors and risk factor clusters in 21 regions, 1990-2010: a systematic analysis for the Global Burden of Disease Study 2010. Lancet 380:2224-2260. 10.1016/s0140-6736(12)61766-8

Linderman GC, Lu J, Lu Y, Sun X, Xu W, Nasir K, Schulz W, Jiang L, and Krumholz HM. 2018. Association of Body Mass Index With Blood Pressure Among 1.7 Million Chinese Adults. JAMA Netw Open 1:e181271. 10.1001/jamanetworkopen.2018.1271

Loret de Mola C, Quispe R, Valle GA, and Poterico JA. 2014. Nutritional transition in children under five years and women of reproductive age: a 15-years trend analysis in Peru. PLoS One 9:e92550. 10.1371/journal.pone.0092550

Martinez R, Lloyd-Sherlock P, Soliz P, Ebrahim S, Vega E, Ordunez P, and McKee M. 2020. Trends in premature avertable mortality from non-communicable diseases for 195 countries and territories, 1990-2017: a population-based study. Lancet Glob Health 8:e511-e523. 10.1016/s2214-109x(20)30035-8

NCD Risk Factor Collaboration (NCD-RisC) - Americas Working Group. 2020. Trends in cardiometabolic risk factors in the Americas between 1980 and 2014: a pooled analysis of population-based surveys. Lancet Glob Health 8:e123-e133. 10.1016/s2214109x(19)30484-x

NCD Risk Factor Collaboration (NCD-RisC). 2017a. Worldwide trends in blood pressure from 1975 to 2015: a pooled analysis of 1479 population-based measurement studies with $19 \cdot 1$ million participants. Lancet 389:37-55. 10.1016/s0140-6736(16)31919-5

NCD Risk Factor Collaboration (NCD-RisC). 2017b. Worldwide trends in body-mass index, underweight, overweight, and obesity from 1975 to 2016: a pooled analysis of 2416 population-based measurement studies in 128.9 million children, adolescents, and adults. Lancet 390:2627-2642. 10.1016/s0140-6736(17)32129-3

NCD Risk Factor Collaboration (NCD-RisC). 2019. Rising rural body-mass index is the main driver of the global obesity epidemic in adults. Nature 569:260-264. 10.1038/s41586019-1171-X

Peixoto Mdo R, Benício MH, Latorre Mdo R, and Jardim PC. 2006. Waist circumference and body mass index as predictors of hypertension. Arq Bras Cardiol 87:462-470. 10.1590/s0066-782x2006001700011

Rao JNK, and Scott AJ. 1984. On Chi-squared tests for multiway contingency tables with cell proportions estimated from survey data. Ann Statist 12:46-60.

Rutstein SO, and Johnson K. 2004. The DHS wealth index. DHS comparative reports no. 6. Calverton, Maryland: ORC Macro.

Takahashi H, Yoshika M, and Yokoi T. 2015. Validation of three automatic devices for the selfmeasurement of blood pressure according to the European Society of Hypertension 
395

396

397

398

399

400

401

402

403

404

405

406

407

408

409

410

411

412
International Protocol revision 2010: the Omron HEM-7130, HEM-7320F, and HEM7500F. Blood Press Monit 20:92-97. 10.1097/mbp.0000000000000096

Tesfaye F, Nawi NG, Van Minh H, Byass P, Berhane Y, Bonita R, and Wall S. 2007. Association between body mass index and blood pressure across three populations in Africa and Asia. J Hum Hypertens 21:28-37. 10.1038/sj.jhh.1002104

Villarreal-Zegarra D, Carrillo-Larco RM, and Bernabe-Ortiz A. 2020. Short-term trends in the prevalence, awareness, treatment, and control of arterial hypertension in Peru. J Hum Hypertens doi.org/10.1038/s41371-020-0361-1. 10.1038/s41371-020-0361-1

West BT, Berglund P, and Heeringa SG. 2008. A closer examination of subpopulation analysis of complex-sample survey data. Stata J 8:520-531.

Williams R. 2012. Using the margins command to estimate and interpret adjusted predictions and marginal effects. Stata J 12:308-331.

Zavala-Loayza JA, Benziger CP, Cárdenas MK, Carrillo-Larco RM, Bernabé-Ortiz A, Gilman RH, Checkley W, and Miranda JJ. 2016. Characteristics Associated With Antihypertensive Treatment and Blood Pressure Control: A Population-Based Follow-Up Study in Peru. Glob Heart 11:109-119. 10.1016/j.gheart.2015.12.002 


\section{Figures' legend}

414 Figure 1 A-B: Body mass index and (A) systolic and (B) diastolic blood pressure

415 Figure 2 A-F: Association between body mass index and systolic blood pressure according to 416 socio-demographic variables

417 Figure 3 A-F: Association between body mass index and diastolic blood pressure according to 418 socio-demographic variables

\section{Supporting information}

421 Statistical approach: Modeling the association between body mass index and blood pressure 422 levels.

423 Table S1. Overall association between body mass index and blood pressure: adjusted models

424 Table S2. Association between body mass index and blood pressure by sex: adjusted models

425 Table S3. Association between body mass index and blood pressure by age categories: adjusted 426 models

427 Table S4. Association between body mass index and blood pressure by education level: 428 adjusted models

429 Table S5. Association between body mass index and blood pressure by socioeconomic position: 430 adjusted models

431 Table S6. Association between body mass index and blood pressure by area: adjusted models

432 Table S7. Association between body mass index and blood pressure by altitude: adjusted models

433 Table S8. Estimation of blood pressure levels according to body mass index (BMI) by age 434 group. 
435 Table S9. Estimation of blood pressure levels according to body mass index (BMI) by education 436 level (in years).

437 Table S10. Estimation of blood pressure levels according to body mass index (BMI) by 438 socioeconomic position.

439 Table S11. Estimation of blood pressure levels according to body mass index (BMI) by study 440 area.

441 Table S12. Estimation of blood pressure levels according to body mass index (BMI) by altitude. 


\section{Table 1 (on next page)}

Description of the study population by sex comparison considering complex sampling design 
1

2 Table 1: Description of the study population by sex comparison considering complex 3 sampling design

4

\begin{tabular}{|c|c|c|c|}
\hline & $\begin{array}{c}\text { Females } \\
(\mathrm{n}=\mathbf{8 9 , 3 7 6 )}\end{array}$ & $\begin{array}{c}\text { Males } \\
(\mathrm{n}=\mathbf{7 0 , 5 3 8})\end{array}$ & p-value \\
\hline \multicolumn{4}{|l|}{ Age } \\
\hline Mean (SD) & $44.3(16.9)$ & $44.4(17.2)$ & 0.51 \\
\hline \multicolumn{4}{|l|}{ Age (categories) } \\
\hline$<40$ years & $51,232(46.5 \%)$ & $36,727(45.8 \%)$ & 0.31 \\
\hline $40-59$ years & $24,553(33.1 \%)$ & $22,188(33.5 \%)$ & \\
\hline$\geq 60$ years & $13,591(20.4 \%)$ & $11,623(20.7 \%)$ & \\
\hline \multicolumn{4}{|l|}{ Education level } \\
\hline$<7$ years & $27,034(30.4 \%)$ & $18,093(23.4 \%)$ & $<0.001$ \\
\hline $7-11$ years & $32,046(36.5 \%)$ & $30,114(41.6 \%)$ & \\
\hline$\geq 12$ years & $24,479(33.1 \%)$ & $20,970(35.0 \%)$ & \\
\hline \multicolumn{4}{|l|}{ Socioeconomic position (assets) } \\
\hline Low & $29,107(23.6 \%)$ & $24,070(24.6 \%)$ & 0.002 \\
\hline Middle & $30,201(30.1 \%)$ & $23,557(30.3 \%)$ & \\
\hline High & $30,068(46.3 \%)$ & $22,911(45.1 \%)$ & \\
\hline \multicolumn{4}{|l|}{ Study area } \\
\hline Rural & $30,142(24.1 \%)$ & $25,632(25.4 \%)$ & $<0.001$ \\
\hline Urban & $59,234(75.9 \%)$ & $44,906(74.6 \%)$ & \\
\hline \multicolumn{4}{|l|}{ Altitude } \\
\hline$\leq 500$ m.a.s.1. & $43,316(59.9 \%)$ & $34,757(61.6 \%)$ & $<0.001$ \\
\hline $501-2500$ m.a.s.1. & $17,850(15.4 \%)$ & $14,805(16.0 \%)$ & \\
\hline$\geq 2501$ m.a.s.1 & $28,210(24.7 \%)$ & $20,976(22.4 \%)$ & \\
\hline \multicolumn{4}{|l|}{ Body mass index } \\
\hline Mean (SD) & $27.5(5.0)$ & $26.6(4.4)$ & $<0.001$ \\
\hline \multicolumn{4}{|l|}{ Body mass index (categories) } \\
\hline Normal $\left(<25 \mathrm{Kg} / \mathrm{m}^{2}\right)$ & $30,048(32.4 \%)$ & $29,208(38.0 \%)$ & $<0.001$ \\
\hline Overweight $\left(25\right.$ to $\left.<30 \mathrm{Kg} / \mathrm{m}^{2}\right)$ & $36,006(40.4 \%)$ & $29,276(43.0 \%)$ & \\
\hline Obese $\left(\geq 30 \mathrm{Kg} / \mathrm{m}^{2}\right)$ & $23,322(27.2 \%)$ & $12,054(19.0 \%)$ & \\
\hline \multicolumn{4}{|l|}{ Blood pressure levels } \\
\hline Systolic blood pressure, mean (SD) & $118.4(16.7)$ & $127.4(15.3)$ & $<0.001$ \\
\hline Diastolic blood pressure, mean (SD) & $70.3(9.3)$ & $74.7(9.9)$ & $<0.001$ \\
\hline \multicolumn{4}{|l|}{ Hypertension } \\
\hline Yes & $13,690(19.5 \%)$ & $13,660(23.2 \%)$ & $<0.001$ \\
\hline
\end{tabular}

$5 \mathrm{SD}=$ Standard deviation; m.a.s.l. $=$ meters above the sea level 


\section{Table 2 (on next page)}

Estimation of blood pressure levels according to body mass index (BMI): in the total sample and excluding those with anti-hypertensive medication 
2

3 Table 2: Estimation of blood pressure levels according to body mass index (BMI): in the total sample and excluding those with anti-hypertensive medication

5

\begin{tabular}{|c|c|c|}
\hline $\begin{array}{l}\text { BMI (in } \\
\left.\mathrm{Kg} / \mathbf{m}^{2}\right)\end{array}$ & In the overall sample & $\begin{array}{l}\text { Only those without } \\
\text { antihypertensive medication }\end{array}$ \\
\hline \multicolumn{3}{|c|}{ Systolic blood pressure (mm Hg) } \\
\hline 10 & $98.5(97.2-99.9)$ & $98.5(97.2-99.8)$ \\
\hline 15 & $107.0(106.3-107.7)$ & $106.8(106.1-107.5)$ \\
\hline 20 & $114.2(113.9-114.5)$ & $113.7(113.4-114.0)$ \\
\hline 25 & $120.0(119.8-120.2)$ & $119.4(119.2-119.6)$ \\
\hline 30 & $124.5(124.3-124.7)$ & $123.8(123.6-124.0)$ \\
\hline 35 & $127.7(127.4-128.0)$ & $126.9(126.6-127.1)$ \\
\hline 40 & $129.6(128.9-130.2)$ & $128.6(128.0-129.2)$ \\
\hline 45 & $130.1(129.0-131.2)$ & $129.1(128.0-130.2)$ \\
\hline 50 & $129.3(127.4-131.2)$ & $128.3(126.5-130.1)$ \\
\hline \multicolumn{3}{|c|}{ Diastolic blood pressure ( $\mathrm{mm} \mathrm{Hg}$ ) } \\
\hline 10 & $56.2(56.4-58.0)$ & $57.1(56.3-58.0)$ \\
\hline 15 & $62.5(62.1-63.0)$ & $62.4(62.0-62.9)$ \\
\hline 20 & $67.1(66.9-67.3)$ & $67.0(66.8-67.1)$ \\
\hline 25 & $70.9(70.8-71.0)$ & $70.7(70.6-70.8)$ \\
\hline 30 & $73.9(73.8-74.0)$ & $73.7(73.6-73.8)$ \\
\hline 35 & $76.1(75.9-76.2)$ & $75.9(75.7-76.1)$ \\
\hline 40 & $77.5(77.1-77.8)$ & $77.3(76.9-77.7)$ \\
\hline 45 & $78.1(77.4-78.8)$ & $78.0(77.2-78.7)$ \\
\hline 50 & $77.9(76.7-79.0)$ & $77.8(76.6-79.0)$ \\
\hline
\end{tabular}

7 Marginal estimates were built on adjusted models. 


\section{Table 3 (on next page)}

Estimation of blood pressure levels according to body mass index (BMI) by sex 
Table 3: Estimation of blood pressure levels according to body mass index (BMI) by sex

\begin{tabular}{|c|c|c|c|c|}
\hline \multirow[b]{2}{*}{$\begin{array}{c}\text { BMI } \\
\left(\text { in } \mathrm{Kg} / \mathrm{m}^{2}\right)\end{array}$} & \multicolumn{2}{|c|}{ Females } & \multicolumn{2}{|c|}{ Males } \\
\hline & In the overall sample & $\begin{array}{c}\text { Only those without } \\
\text { antihypertensive } \\
\text { medication }\end{array}$ & In the overall sample & $\begin{array}{c}\text { Only those without } \\
\text { antihypertensive } \\
\text { medication }\end{array}$ \\
\hline & \multicolumn{4}{|c|}{ Systolic blood pressure $(\mathrm{mm} \mathrm{Hg})$} \\
\hline 10 & $97.0(95.3-98.6)$ & $97.4(95.8-99.0)$ & $100.2(98.0-102.4)$ & $99.6(97.5-101.7)$ \\
\hline 15 & $104.2(103.3-105.1)$ & $104.0(103.2-104.9)$ & $110.2(109.1-111.4)$ & $109.8(108.8-110.9)$ \\
\hline 20 & $110.4(110.0-110.8)$ & $109.8(109.4-110.2)$ & $118.6(118.1-119.0)$ & $118.3(117.9-118.8)$ \\
\hline 25 & $115.5(115.3-115.8)$ & $114.6(114.4-114.8)$ & $125.2(125.0-125.5)$ & $125.0(124.8-125.2)$ \\
\hline 30 & $119.7(119.4-119.9)$ & $118.6(118.3-118.8)$ & $130.2(129.9-130.5)$ & $129.9(129.6-130.2)$ \\
\hline 35 & $122.7(122.4-123.1)$ & $121.6(121.2-121.9)$ & $133.6(133.1-134.1)$ & $133.1(132.6-133.6)$ \\
\hline 40 & $124.8(124.0-125.5)$ & $123.6(122.9-124.4)$ & $135.2(134.1-136.3)$ & $134.4(133.4-135.5)$ \\
\hline 45 & $125.8(124.4-127.1)$ & $124.8(123.5-126.2)$ & $135.2(133.2-137.2)$ & $134.1(132.1-136.0)$ \\
\hline \multirow[t]{2}{*}{50} & $125.8(123.5-128.0)$ & $125.1(122.9-127.3)$ & $133.5(130.2-136.8)$ & $131.9(128.8-135.1)$ \\
\hline & \multicolumn{4}{|c|}{ Diastolic blood pressure (mm Hg) } \\
\hline 10 & $56.8(55.7-57.8)$ & $57.0(55.9-58.0)$ & $58.1(56.7-59.5)$ & $57.7(56.3-59.0)$ \\
\hline 15 & $61.5(60.9-62.0)$ & $61.5(60.9-62.0)$ & $64.0(63.3-64.7)$ & $63.7(63.0-64.4)$ \\
\hline 20 & $65.5(65.2-65.7)$ & $65.3(65.0-65.6)$ & $69.1(68.8-69.4)$ & $68.9(68.6-69.2)$ \\
\hline 25 & $68.8(68.7-68.9)$ & $68.5(68.4-68.7)$ & $73.3(73.2-73.5)$ & $73.2(73.1-73.4)$ \\
\hline 30 & $71.4(71.3-71.6)$ & $71.1(71.0-71.3)$ & $76.8(76.6-77.0)$ & $76.7(76.5-76.9)$ \\
\hline 35 & $73.4(73.2-73.6)$ & $73.1(72.9-73.3)$ & $79.4(79.1-79.8)$ & $79.3(78.9-79.6)$ \\
\hline 40 & $74.7(74.2-75.1)$ & $74.5(74.0-74.9)$ & $81.2(80.5-82.0)$ & $81.0(80.2-81.8)$ \\
\hline 45 & $75.3(74.5-76.1)$ & $75.2(74.4-76.1)$ & $82.2(80.8-83.7)$ & $81.9(80.4-83.3)$ \\
\hline 50 & $75.2(73.8-76.5)$ & $75.3(73.9-76.7)$ & $82.4(80.1-84.7)$ & $81.8(79.5-84.1)$ \\
\hline
\end{tabular}

Marginal estimates were built on adjusted models. 
Figure 1

Body mass index and (A) systolic and (B) diastolic blood pressure
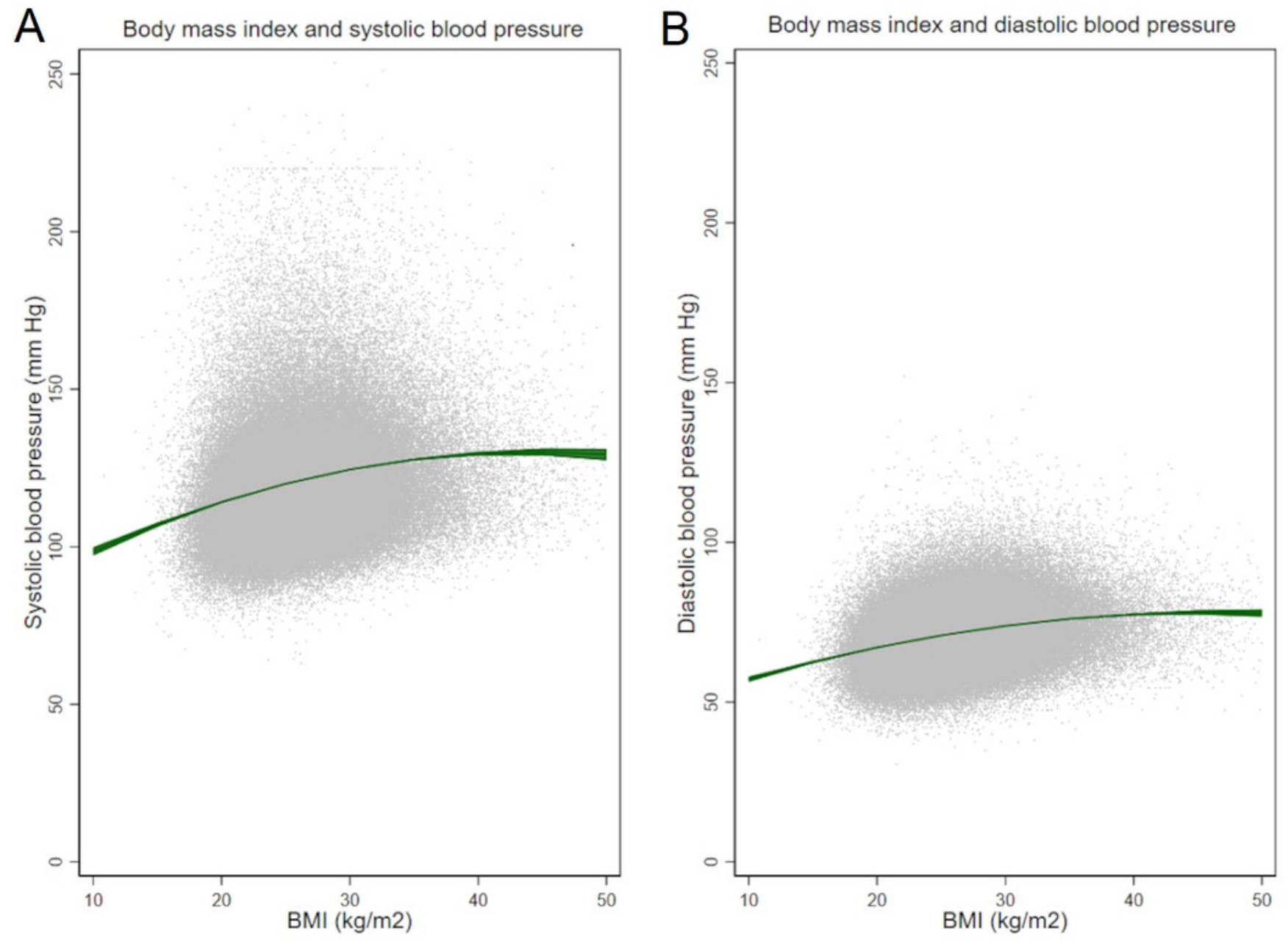
Figure 2

Association between body mass index and systolic blood pressure according to sociodemographic variables

(A) By sex, (B) by age, (C) by education level, (D) by socioeconomic position, (E) by area, and (F) by altitude.
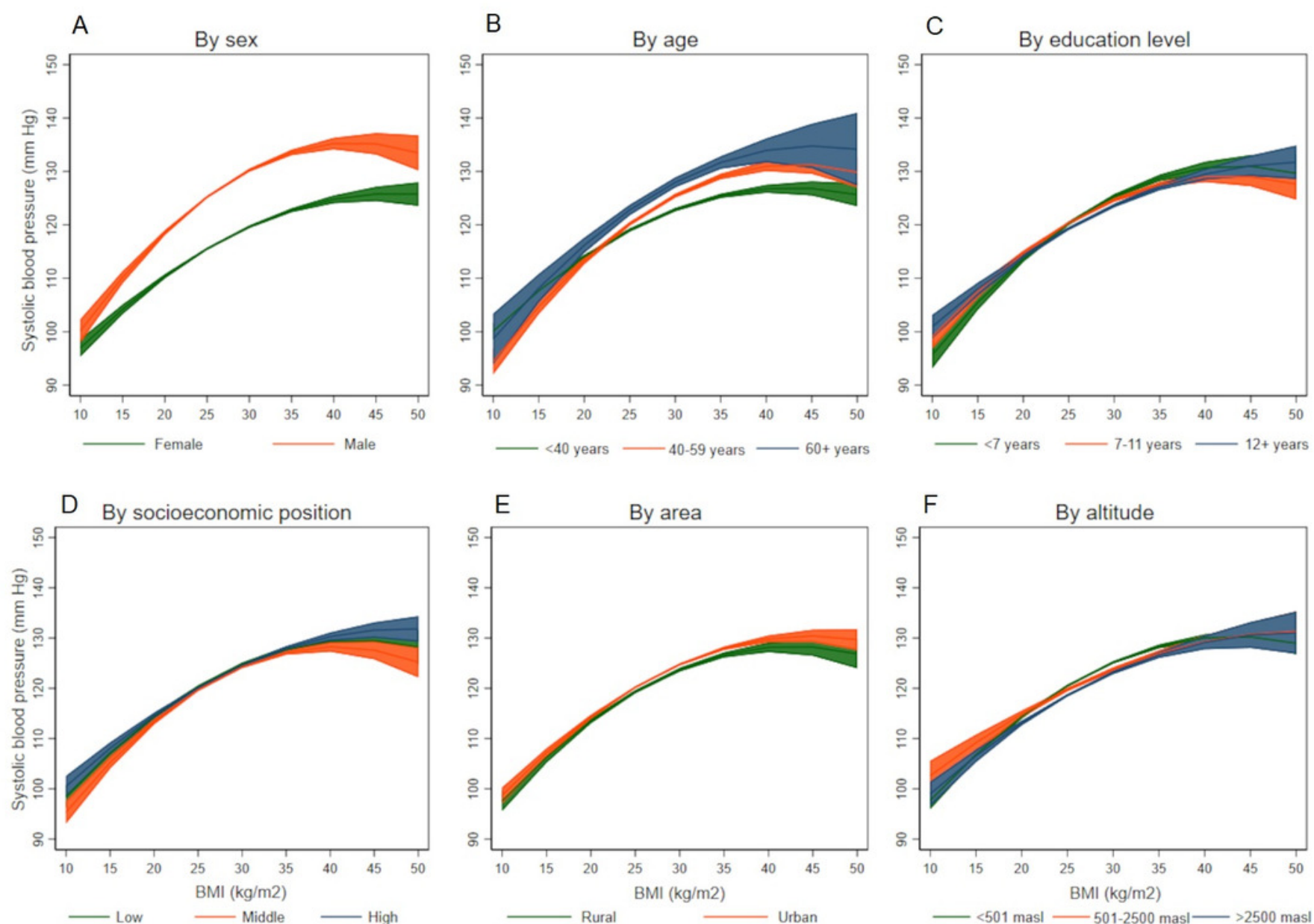
Figure 3

Association between body mass index and diastolic blood pressure according to sociodemographic variables

(A) By sex, (B) by age, (C) by education level, (D) by socioeconomic position, (E) by area, and

(F) by altitude.
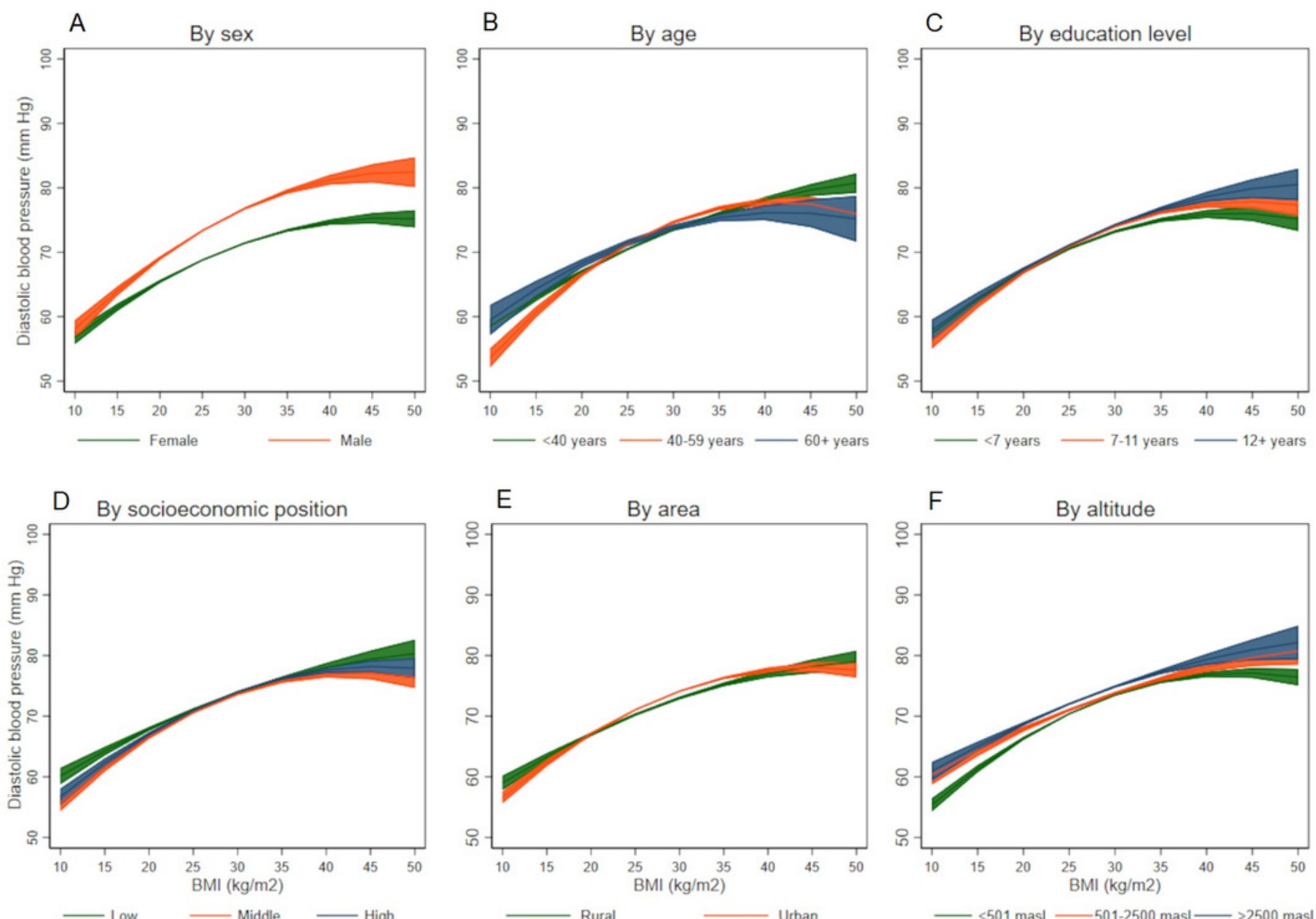